\title{
Interaction Between \\ Ultraviolet Light and $\gamma$-Radiation Damage in the Induction of Mutants of Escherichia coli: the Response in Strains with Normal and Reduced Ability to Repair Ultraviolet Damage
}

\author{
By D. R. DAVIES AND C. F. ARLETT \\ Wantage Research Laboratory (A.E.R.E.), Wantage, Berkshire \\ AND R. J. MUNSON AND B. A. BRIDGES \\ Medical Research Council Radiobiological Research Unit, \\ Harwell, Didcot, Berkshire
}

(Accepted for publication 5 September 1966)

SUMMARY

\begin{abstract}
The exposure of tryptophan-requiring Escherichia coli $\mathrm{B} / \mathrm{r}$ WP 2 to u.v.- and $\gamma$-irradiation (in either order) results in more revertants than would be expected if the two treatments were independent. The excess mutants ("interaction mutants') were produced in increasing number by increasing doses of u.v.or $\gamma$-radiation. Evidence is presented that the interaction occurs post-irradiation. Although the excision-repair and mutation frequency decline systems for u.v. damage are not involved in the interaction itself (since a strain deficient in these systems, $E$. coli wP 2 hcr- $^{-}$, is no less efficient at producing interaction mutants than $E$. coli $/ \mathrm{B}$ / WP 2) the u.v. component involved in interaction is sensitive to one or both of these systems as is shown by the very much lower u.v. doses at which interaction occurs in $E$. coli wP 2 hcr $^{-}$.
\end{abstract}

\section{INTRODUCTION}

It has been recently demonstrated that synergistic interactions occur between ultraviolet light (u.v.) and X-rays for lethal damage in some strains of Escherichia coli (Haynes, 1964). In those strains lacking certain repair mechanisms or in those possessing them but in which the repair processes have been suppressed, this interaction does not occur (Haynes, 1964; Baptist, Haynes \& Uretz, 1966). On the basis of these results it has been postulated that synergism between u.v.- and X-rays involves repair processes. No comparable effort has been made to demonstrate such an interaction in terms of mutational damage. Though the early work of Swanson (1952) on Aspergillus terreus claimed to show such an effect, later work on A. nidulans has failed to substantiate this claim (Arlett, to be published). Doneson \& Shankel (1964) were also unable to demonstrate interaction between u.v.- and $\gamma$-radiation in the production of high-level streptomycin-resistant mutants of E. coli.

It is well recognized that repair of mutational lesions occurs, particularly in reversion to prototrophy, and so a similarity to the responses obtained for lethal damage might be predicted. In the experiments reported here the aim was first to determine 
whether a synergistic interaction occurred, and if it did, to examine the role of repair mechanisms in the process. This has been done by comparing the responses of strains possessing and lacking certain repair mechanisms.

\section{METHODS}

The bacterial strains used were the tryptophan requiring Escherichia coli $\mathbf{B} / \mathbf{r}$ wP 2 (subsequently referred to as the hcr+ strain) and a mutant form of this strain which is deficient for certain dark repair activities $E$. coli wP 2 hcr- $^{-}$(subsequently hor-). The hcr- $^{-}$strain is unable to perform host cell reactivation of bacteriophage, is more sensitive than the hcr ${ }^{+}$strain to both the lethal and mutagenic actions of u.v. (Hill, 1965; Ashwood-Smith \& Bridges, 1966), has a reduced ability to excise thymine dimers from its DNA (Setlow, quoted by Hill, 1965) and exhibits slower mutation frequency decline of u.v.-induced mutants in minimal medium (Munson \& Bridges, 1966 b). (We are grateful to Dr Ruth Hill for providing us with this strain). Logarithmic phase bacteria were used for all experiments. These were grown with aeration at $37^{\circ}$ in a glucose salts medium (M medium of Haas \& Doudney, 1957) supplemented with $10 \mu \mathrm{g} . / \mathrm{ml}$. tryptophan. After reaching a suitable population density $\left(1-3 \times 10^{8} / \mathrm{ml}\right.$.) the bacteria were spun down and resuspended in buffer salts solution ( $M$ medium minus glucose) at $4^{\circ}$; thereafter the bacteria were maintained at this temperature until plated. Counts of viable and mutant organisms were made on the same medium ( $\mathrm{M}$ enriched with $0.75 \mu \mathrm{g} . / \mathrm{ml}$. tryptophan and solidified with $1.5 \%$ agar) following incubation for $48 \mathrm{hr}$ at $37^{\circ}$. All manipulations were done in yellow light or under low light intensities to prevent photoreactivation.

Experiments were performed independently in both laboratories and some inconsistencies in radiation response were noted. These may have been due to slight differences either in biological technique or in the spectra of the two lamps. Each interaction experiment was therefore carried out with a complete set of internal controls thus obviating the need to compare results obtained at different times and in different places.

\section{Sources of radiation}

(a) Ultraviolet-low pressure mercury vapour

(1) A $30 \mathrm{~W}$. Phillips TUV lamp giving an incident dose rate of $45 \mathrm{ergs}^{\mathrm{mm}} \mathrm{m}^{-2} \mathrm{sec}^{-1}$ at $75 \mathrm{~cm}$., the target to lamp distance used.

(2) A Vitreosil (England) lamp in the form of an incomplete circle giving 3.29 ergs $\mathrm{mm} .^{-2} \mathrm{sec}^{-1}$ at $90 \mathrm{~cm}$.

(b) $\gamma-\mathrm{ray}-{ }^{60} \mathrm{Co}$

(1) A $4000 \mathrm{Ci}$ 'Hot Spot' (UKAEA, Harwell) giving a dose rate of $17 \mathrm{krad}$. min. ${ }^{-1}$.

(2) Combination of two $250 \mathrm{Ci}$ sources giving a dose rate of $5 \mathrm{krad} . \mathrm{min} .^{-1}$.

\section{RESULTS}

(a) $\mathrm{Hcr}^{+}$strain

(1) Ultraviolet followed by $\gamma$-radiation

Typical responses to u.v.- and to $\gamma$-radiation in terms of survival and of mutation to prototrophy are shown in Fig. 1. The u.v. responses represent those obtained in the dark, and the $\gamma$ results, those obtained following vigorous bubbling of the cells with 
oxygen both before and during irradiation. Within the range of $\gamma$ doses the mutational response was linear, whereas for u.v. mutation induction the yield increased in proportion to the square of the dose.

To test whether a synergistic interaction occurred cells were first exposed to a low dose of u.v. and then to a range of $\gamma$ doses. Other samples were given either the u.v. dose alone or the range of $\gamma$ doses alone.

In different experiments the time interval between doses varied from a few minutes to over an hour but there was no significant difference in the responses obtained. A low u.v. dose had little effect on the survival characteristics of the cells, but enhanced

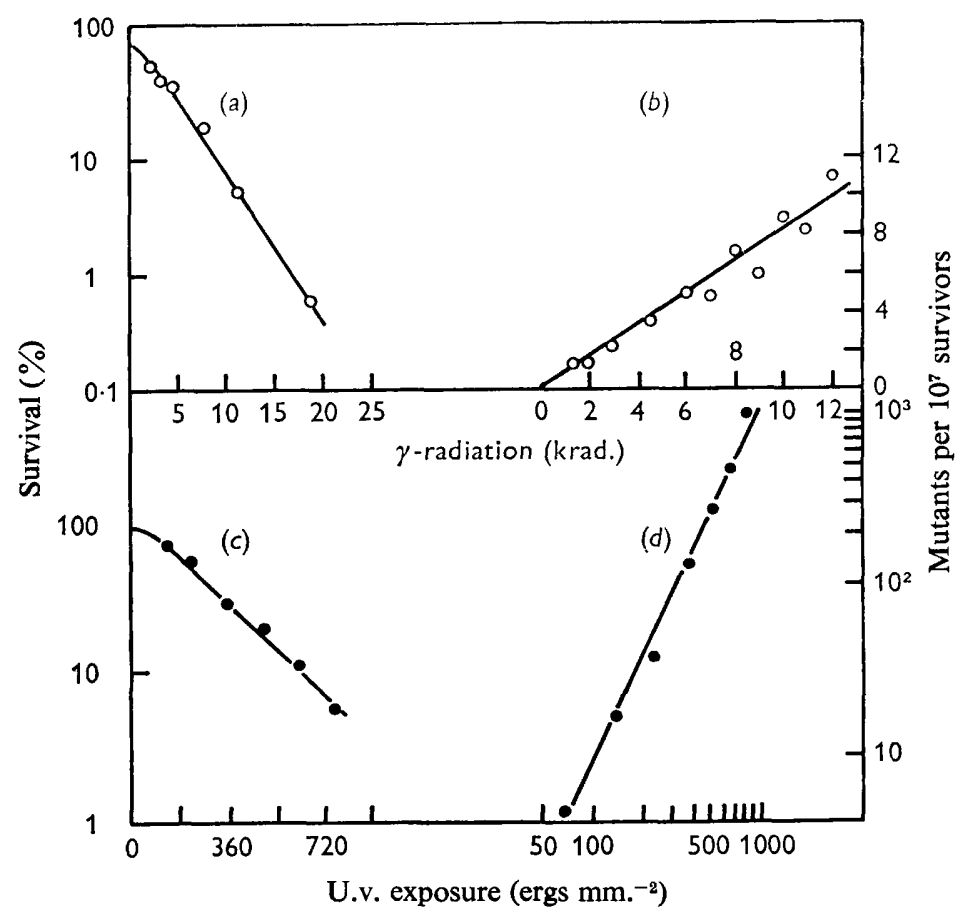

Fig. 1. ( $a$ and $b$ ). Lethal and mutagenic action of $\gamma$-radiation on $E$. coli WP2 her ${ }^{+}$. ( $c$ and $d$ ) Lethal and mutagenic action of u.v. on $E$. coli wP 2 hcr $^{+}$. Single representative experiments.

the yield of mutations induced by later $\gamma$ doses. This enhancement can be best demonstrated by plotting the number of interaction mutants produced for different doses of $\gamma$ radiation after a constant u.v. dose. The results of a typical experiment are given in Fig. 2. For the purpose of this paper the frequency of interaction mutants per survivor is defined as the number of mutants per survivor induced by a combined u.v. $-\gamma$ treatment less the number of mutants per survivor induced by each treatment given separately to similar bacterial suspensions. In the experiment shown the frequency of these interaction mutants increased linearly with dose, though in other experiments there was some indication of non-linearity.

\section{(b) $\mathrm{Hcr}^{-}$strain}

Typical response curves for u.v.- and $\gamma$-radiation alone are shown in Fig. 3. It can be seen that, in contrast to its sensitivity to u.v., the hor ${ }^{-}$strain does not differ signifi- 
cantly from the hcr ${ }^{+}$in its sensitivity to $\gamma$-radiation under these conditions, confirming the observations of Bridges \& Munson (1966). Results of interaction experiments with the $\mathrm{hcr}^{-}$strain were very similar to those with the hor ${ }^{+}$strain except that comparable interaction was obtained at very much lower u.v. doses (Fig. 4).

A feature of the hor- results is that an appreciable number of interaction mutants could be obtained following doses of radiation where the lethal effect was small. This makes it possible to eliminate the possibility that 'interaction mutants' are artifacts arising from the selection by $\gamma$-radiation of u.v. induced revertants possessing abnormally high resistance to the lethal action of $\gamma$-radiation.

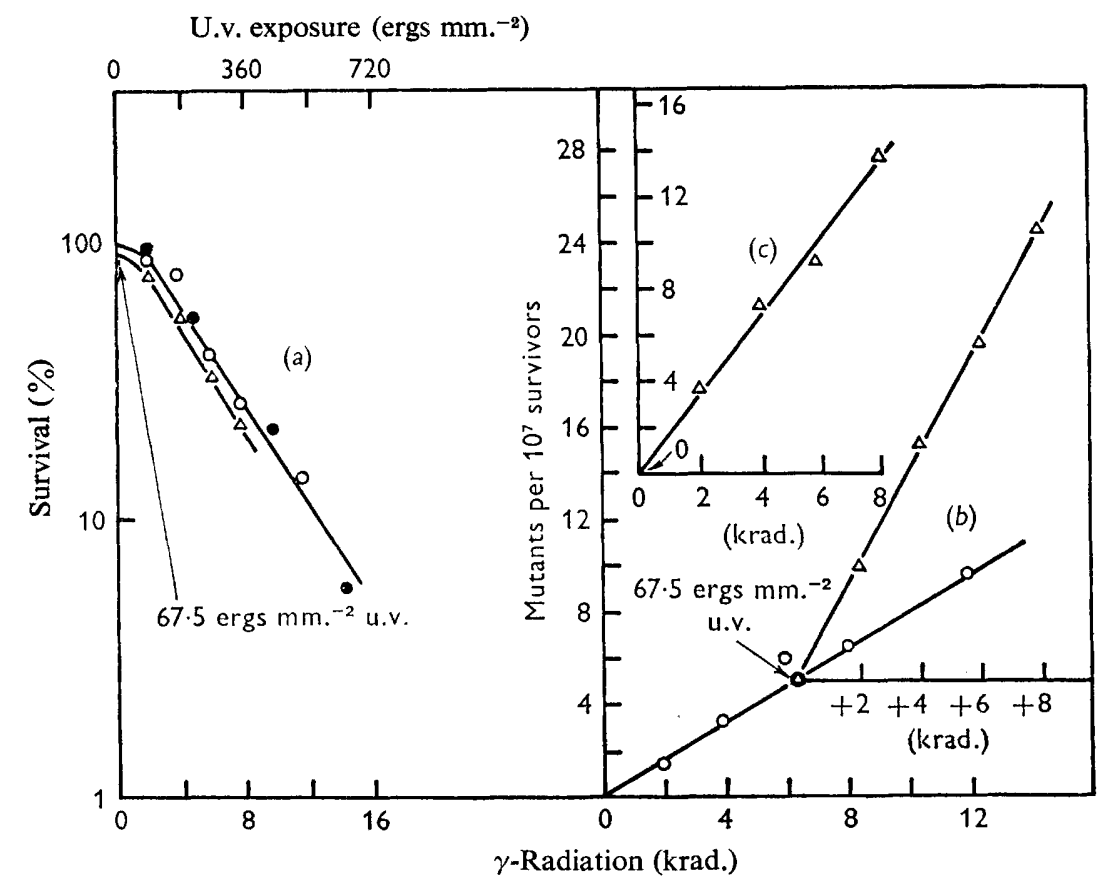

Fig. 2. (a) Lethal effects of $\gamma$ - (O), u.v.- ( () and combined u.v.- and $\gamma-(\triangle)$ radiations on E. coli WP 2 hcr $^{+}$. (b) Mutagenic effect of $\gamma-(O)$ and of combined u.v.- and $\gamma-(\triangle)$ radiations on $E$. coli WP $2 \mathrm{hcr}^{+}$. (c) Yield of interaction mutants by a range of $\gamma$-radiation doses following a dose of 67.5 ergs mm. ${ }^{-2}$ u.v. to $E$, coli WP 2 her $^{+}$.

\section{(c) Dependence on preliminary u.v. dose}

With both the hor ${ }^{+}$and hor ${ }^{-}$strains a larger u.v. pretreatment enhanced markedly the frequency of interaction mutants. With the hor ${ }^{+}$, a treatment with $500 \mathrm{ergs} \mathrm{mm}^{-{ }^{-2} \mathrm{sec}^{-1}}$ reduced survival to $20 \%$ of the unirradiated control, and after this pretreatment the survival curve obtained with a range of $\gamma$ doses had an increased slope. This confirms the observations of Haynes (1964). Under his conditions no shoulder was obtained on the $\gamma$-radiation curve. Under our conditions the shoulder would appear to be due to the presence of several segregating targets within the bacteria (Munson \& Bridges, 1966 a) and not to a dose-dependent repair system as postulated by Haynes (1964) to explain his u.v.-survival curve. If the $\gamma$-radiation targets were chromosomal, the reduction of the shoulder on the $\gamma$-survival curve by low doses of u.v. would be expected. 


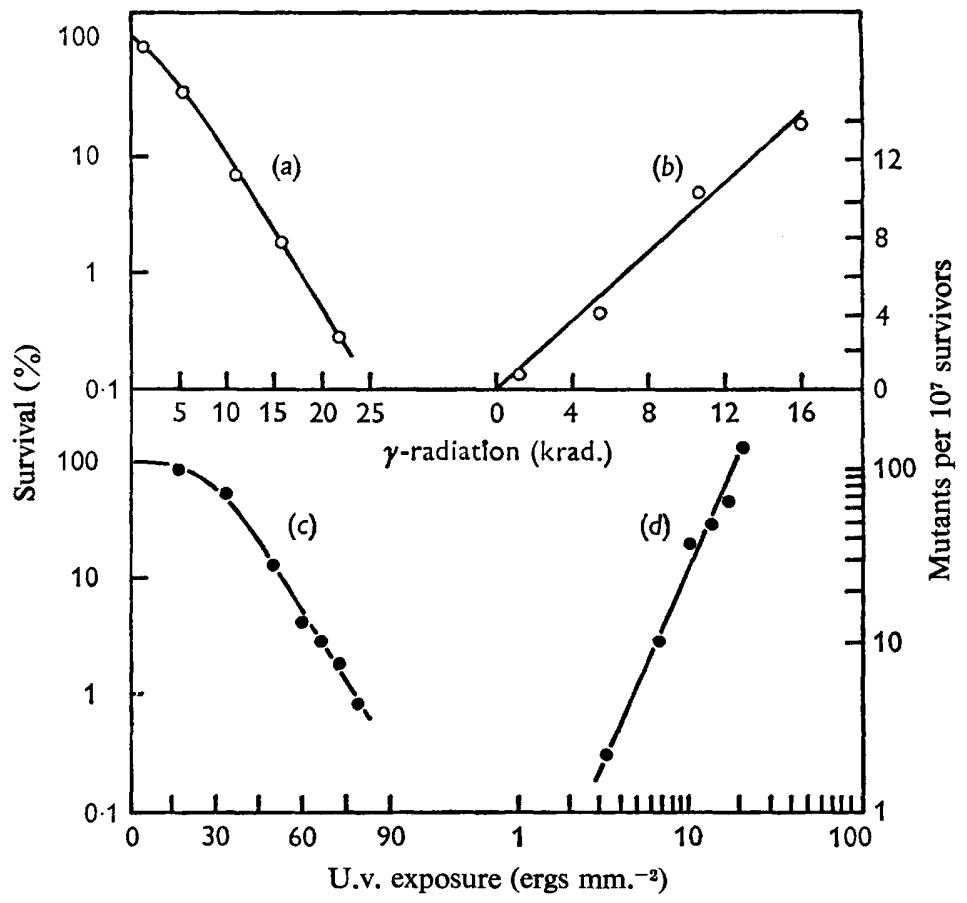

Fig. 3. ( $a$ and $b$ ) Lethal and mutagenic action of $\gamma$-radiation on $E$. coli WP 2 hcr-. ( $c$ and $d$ ) Lethal and mutagenic action of u.v.-radiation on $E$. coli WP2 hcr-. Single representative experiments.

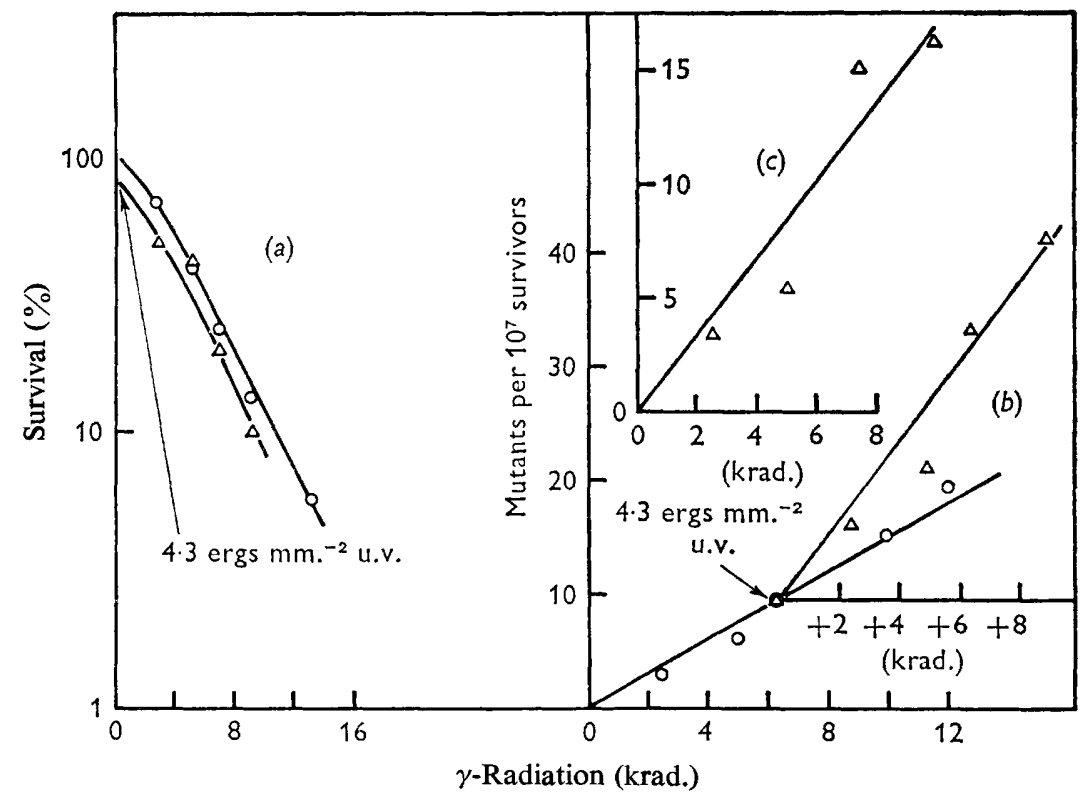

Fig. 4. (a) Lethal effects of $\gamma-(O)$ and combined u.v.- and $\gamma-(\triangle)$ radiations on $E$. coli WP2 hcr-. (b) Mutagenic effects of $\gamma-(O)$ and of combined u.v.- and $\gamma-(\triangle)$ radiations on $E$. coli WP 2 hcr-. (c) Yield of interaction mutants by a range of $\gamma$-radiation doses following a dose of 4.3 ergs mm..$^{-2}$ u.v. to $E$. coli $\mathrm{WP} 2$ hcr- $^{-}$. 
The frequency of interaction mutants induced by a series of $\gamma$-doses following high or low u.v. doses is shown in Fig. 5. The frequency appeared not to be proportional to the dose.

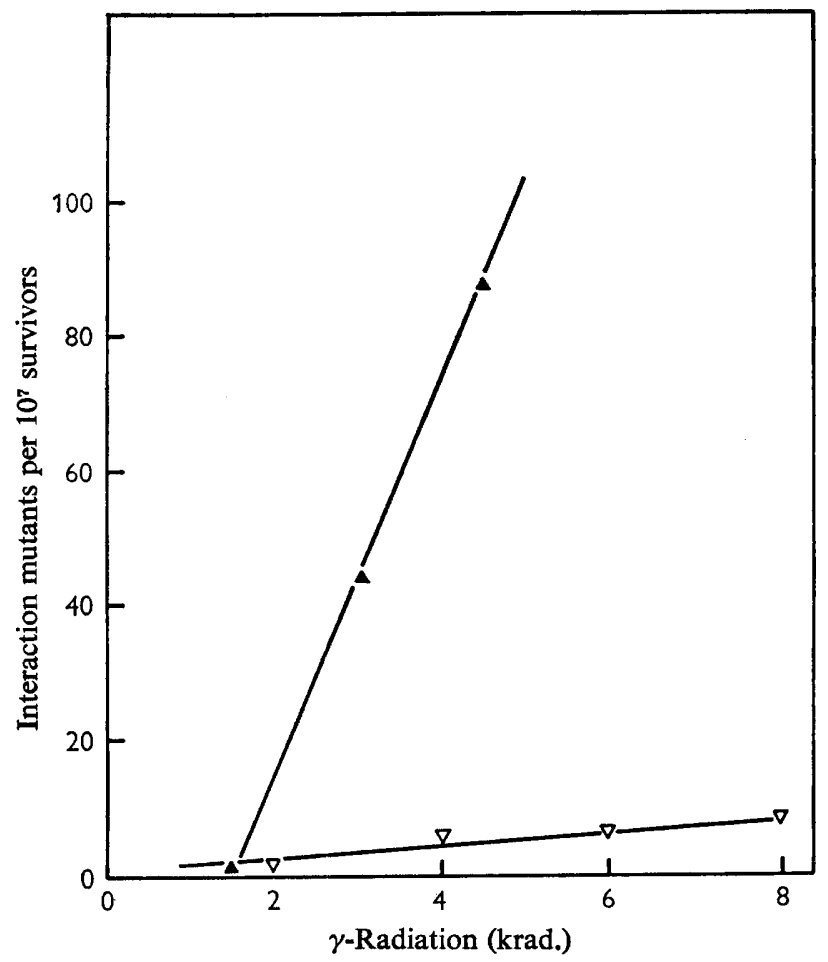

Fig. 5. Yield of interaction mutants by a range of $\gamma$-radiation doses following a u.v. dose of $67 \cdot 5(\nabla)$ and $495(\Delta)$ ergs mm. ${ }^{-2}$ to E. coli WP 2 hcr'.

Table 1. Frequency of induced prototrophs following $\gamma$-radiation alone, u.v. alone or u.v. followed by $\gamma$-radiation

\begin{tabular}{|c|c|c|c|c|c|}
\hline \multicolumn{2}{|c|}{ Treatment } & \multirow{2}{*}{$\begin{array}{l}\text { Total no. of } \\
\text { prototrophic } \\
\text { colonies } \\
\text { scored }\end{array}$} & \multirow[b]{2}{*}{$\begin{array}{l}\text { Surviving } \\
\text { fraction }\end{array}$} & \multirow{2}{*}{$\begin{array}{c}\text { Induced } \\
\text { prototrophs } \\
\text { per } 10^{7} \\
\text { survivors }\end{array}$} & \multirow{2}{*}{$\begin{array}{c}\text { Interactior } \\
\text { mutants } \\
\text { per } 10^{7} \\
\text { survivors }\end{array}$} \\
\hline $\begin{array}{c}\text { u.v. } \\
\text { (ergs } \mathrm{mm} .^{-2} \text { ) }\end{array}$ & $\begin{array}{c}\gamma \\
\text { (krad.) }\end{array}$ & & & & \\
\hline 0 & 0 & 31 & 1.00 & - & - \\
\hline 0 & 2 & 190 & 0.852 & $1 \cdot 6$ & - \\
\hline 0 & 4 & 306 & 0.674 & $3 \cdot 5$ & - \\
\hline 0 & 6 & 317 & 0.394 & $6 \cdot 2$ & - \\
\hline 0 & 8 & 233 & 0.262 & $6 \cdot 5$ & - \\
\hline 0 & 12 & 204 & $0 \cdot 150$ & 9.8 & - \\
\hline
\end{tabular}

Number of bacteria plated per treatment $=1 \cdot 18 \times 10^{\circ}$.

$\begin{array}{rrrrrr}0 & 0 & 10 & 1 \cdot 00 & - & - \\ 67 \cdot 5 & 0 & 63 & 0 \cdot 926 & 5 \cdot 2 & - \\ 67 \cdot 5 & 2 & 891 & 0 \cdot 761 & 10 \cdot 5 & 3 \cdot 7 \\ 67 \cdot 5 & 4 & 973 & 0 \cdot 545 & 16 \cdot 0 & 7 \cdot 3 \\ 67 \cdot 5 & 6 & 762 & 0.332 & 20 \cdot 6 & 9 \cdot 2 \\ 67 \cdot 5 & 8 & 645 & 0 \cdot 225 & 25 \cdot 6 & 13.9\end{array}$

Number of bacteria plated per treatment $=1 \cdot 10 \times 10^{9}$. 
When the production of interaction mutants by a series of u.v. doses each followed by the same $\gamma$-dose was compared with the production of mutants by the u.v. dose alone, it was apparent that the hor- strain is roughly twenty times more sensitive to u.v. than the her ${ }^{+}$strain for both u.v. and interaction mutants.

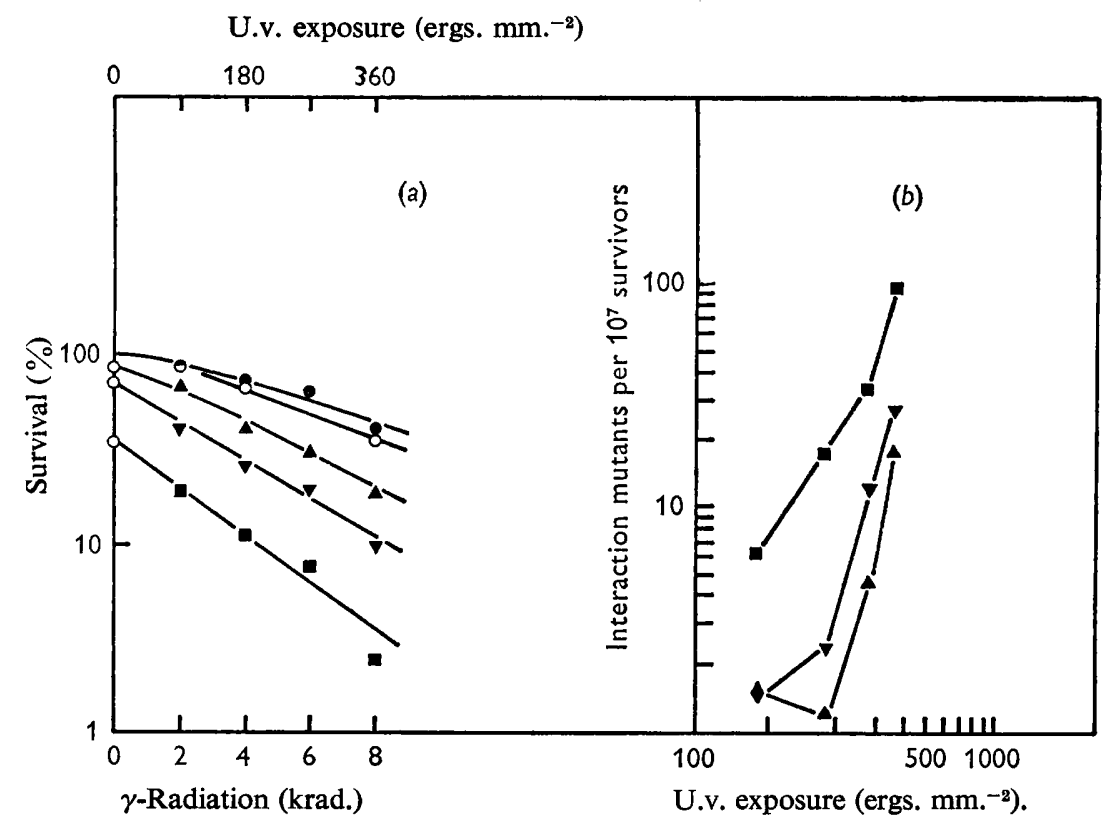

Fig. 6. (a) Lethal effects of $\gamma-(O)$, u.v.- ( $(\bullet)$, and combined $\gamma-(\Delta, 2$ krad.; $\nabla, 4$ krad.; $\square$, $8 \mathrm{krad}$.) and u.v.- radiations on $E$. coli wP $2 \mathrm{hcr}^{+}$. (b) Yield of interaction mutants in $E$. coli

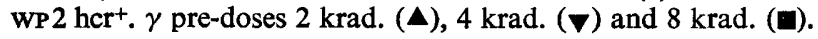

\section{(2) $\gamma$-followed by ultraviolet-irradiation}

The effect of reversing the order of the two irradiations was examined using the $\mathrm{hcr}^{+}$strain. Samples were exposed to 2,4 , or $8 \mathrm{krad}$. of $\gamma$-radiation and then to a range of u.v. doses. The shoulder of the u.v.-survival curve became smaller with increasing $\gamma$ dose and disappeared after $8 \mathrm{krad}$. (Fig. 6). A synergistic interaction was also evident for the induced mutants (Fig. 6). The yield of interaction mutants clearly increased in a non-linear manner with respect to both the u.v. doses and the preliminary $\gamma$ dose. Other experiments indicated that the frequency of interaction mutants obtained with any combination of u.v. and $\gamma$ doses was similar irrespective of the order in which they were given.

Finally the effect of varying the time interval between the $\gamma$ - and u.v.-irradiation treatments was examined. Organisms were pretreated with $8 \mathrm{krad}$. of $\gamma$-radiation then held in the usual buffer at $4^{\circ}$ for intervals of 5-120 min. prior to exposure to 230 or 360 ergs $\mathrm{mm}^{-2}$ u.v. There was no significant effect of interval between treatments on the response (Table 2).

One can summarize the main features of the results of the present experiments as follows:

(a) Pretreatment of cells of the hcr ${ }^{+}$and hcr- strains with low doses of u.v. resulted in an enhancement of the yield of mutations induced by a later dose of $\gamma$-radiation. 
(b) Much lower doses of u.v. were required to induce this synergistic interaction in the case of the her- than of the her' strain.

(c) The higher the pretreatment dose the greater the frequency of interaction mutants.

(d) There was no effect of the time interval between treatments under the holding conditions used.

(e) When $\mathrm{hcr}^{+}$cells were pretreated with $\gamma$-radiation prior to exposure to u.v. there was also an enhanced yield of mutations similar in magnitude to that when the u.v. exposure was given first. Again the interval between the treatments did not affect the frequency of interaction mutants.

Table 2. Effect of interval of time between exposure to $\gamma$-radiation and u.v. on the induction of prototrophs. The bacteria were held at $4^{\circ}$ in a buffered salts solution between treatments

\begin{tabular}{|c|c|c|c|c|c|c|c|}
\hline \multicolumn{2}{|c|}{ Treatments } & \multirow{2}{*}{$\begin{array}{c}\text { Interval } \\
\text { between } \\
\text { treatments } \\
\text { (min.) }\end{array}$} & \multirow{2}{*}{$\begin{array}{c}\text { Spontaneous } \\
\text { plate } \\
\text { mutants }\end{array}$} & \multirow{2}{*}{$\begin{array}{l}\text { Total no. of } \\
\text { prototrophic } \\
\text { colonies } \\
\text { scored }\end{array}$} & \multirow[b]{2}{*}{$\begin{array}{l}\text { Surviving } \\
\text { fraction }\end{array}$} & \multirow{2}{*}{$\begin{array}{c}\text { Total no. of } \\
\text { bacteria } \\
\text { plated } \\
\left(\times 10^{9}\right)\end{array}$} & \multirow{2}{*}{$\begin{array}{c}\text { Induced } \\
\text { prototrophs } \\
\text { per } 10^{7} \\
\text { survivors }\end{array}$} \\
\hline$\underset{\text { (krad.) }}{\gamma}$ & $\begin{array}{l}\text { u.v. } \\
\text { (ergs mm. }^{-2} \text { ) }\end{array}$ & & & & & & \\
\hline 8 & 0 & $\begin{array}{l}\text { At start of } \\
\text { experiment } \\
\text { At finish of }\end{array}$ & 21 & 238 & $0 \cdot 313$ & 1.08 & $6 \cdot 4$ \\
\hline & & experiment & 21 & 224 & $0 \cdot 306$ & 1.08 & $6 \cdot 1$ \\
\hline 0 & 360 & $\begin{array}{l}\text { At start of } \\
\text { experiment } \\
\text { At finish of }\end{array}$ & 16 & 1723 & 0.397 & $1 \cdot 24$ & 35 \\
\hline & & experiment & 15 & 1590 & 0.350 & 1.06 & 43 \\
\hline 8 & 270 & $\begin{array}{r}5 \\
30 \\
60 \\
120\end{array}$ & $\begin{array}{l}11 \\
21 \\
21 \\
21\end{array}$ & $\begin{array}{l}668 \\
659 \\
785 \\
804\end{array}$ & $\begin{array}{l}0.118 \\
0.090 \\
0 \cdot 104 \\
0 \cdot 120\end{array}$ & $\begin{array}{l}0.90 \\
1 \cdot 08 \\
1 \cdot 08 \\
1 \cdot 06\end{array}$ & $\begin{array}{l}62 \\
66 \\
68 \\
61\end{array}$ \\
\hline 8 & 360 & $\begin{array}{r}5 \\
30 \\
60 \\
120\end{array}$ & $\begin{array}{l}11 \\
15 \\
15 \\
15\end{array}$ & $\begin{array}{r}748 \\
891 \\
1018 \\
1035\end{array}$ & $\begin{array}{l}0.061 \\
0.063 \\
0.074 \\
0.059\end{array}$ & $\begin{array}{l}0.90 \\
1.06 \\
1.06 \\
1.06\end{array}$ & $\begin{array}{l}135 \\
131 \\
128 \\
164\end{array}$ \\
\hline
\end{tabular}

\section{DISCUSSION}

One possible interpretation of the data involves the assumption that the first irradiation sensitizes the DNA itself such that the second irradiation induces a higher yield of mutational lesions. But as the order of irradiations is immaterial it seems more likely that the interaction takes place after the second irradiation has been given. The fact that holding the cells at $4^{\circ}$ for different periods between irradiations had no effect on the yield of interaction mutants is not inconsistent with the concept that the events which resulted in the enhanced yield of mutations took place at the time when the cells were returned to $37^{\circ}$. If this is so, two alternative interpretations may be made: (a) that the synergistic interaction is due to accelerated rates of fixation (and therefore diminished possibility of loss of mutants) following combined treatments, or $(b)$ that it is associated with an inhibition or inactivation of repair processes. The first of these alternatives seems untenable. Fixation is generally considered to be associated with the onset of DNA synthesis (Lieb, 1960; Weatherwax \& Landman, 1960; Witkin, 1961) 
and there is no reason to assume that this would occur more rapidly after a combined than after a single treatment. Furthermore, the onset of DNA synthesis after irradiation is delayed to a far greater extent in hcr- in than hor' ${ }^{+}$strains (Setlow, 1964) and so the onset of fixation might be similarly delayed in the former. The synergistic interaction would therefore seem to be associated with a decrease in repair of premutational damage after irradiation. This is supported by the observation that interaction was observed after much lower doses with the hor ${ }^{-}$than the hor ${ }^{+}$strain, the difference between these strains lying not in their inherent sensitivity to damage but in their capacity for repairing this damage (Hill, 1965).

Bridges (1966) has recently proposed a model for the induction of prototrophic mutations by u.v., in which he seeks to interpret the second-order dependence on dose in terms of a requirement for two events. The first of these (event A) is not of itself a mutational lesion, but it can interfere with the repair of the mutational event (B). The linear and low level of response obtained with $\mathrm{X}$ - or $\gamma$-radiation could in these terms be attributed to a limitation of the production of 'type A' events; u.v. pretreatment would then have the effect of removing this limitation. Following a $\gamma$-irradiation the yield of mutations could be enhanced possibly by the additional frequency of 'type B' events or the production of other ('type A') lesions which interfere with u.v.-induced 'type B' events. However, the specific events which Bridges has described could not be induced by $\gamma$-radiation. ' $A$ ' is a 'thymine-dimer' type of lesion and ' $B$ ' is characterized e.g. by its ability to be repaired by the mutation frequency decline system and by its susceptibility to acriflavine; neither of these affects $\gamma$-induced mutational lesions (Kada, Brun \& Marcovich, 1960; Bridges \& Munson, 1964; Munson \& Bridges, 1966 b). Thus although this specific interpretation in terms of ' $A$ ' and ' $B$ ' events cannot be made, the concept of an interference at the level of repair is a useful one in the context of the present results.

The next feature to consider is the type of repair process that could be interfered with. One may interpret the results either as indicating that the u.v. treatment enhances the yield of $\gamma$-induced mutations, or that the range of $\gamma$ doses allows an expression of an increasing number of mutations induced by the u.v. doses. In other words, the interaction mutants could be either basically $\gamma$ - or u.v.-induced. Although the present results do not bear on this, indications that the induction of interaction mutants has the properties of u.v. mutagenesis are presented in the accompanying paper (Bridges, Munson, Arlett \& Davies, 1967). The fact that u.v. $-\gamma$ interaction occurs in both the $\mathrm{hcr}^{-}$and $\mathrm{hcr}^{+}$strains indicates that the excision-repair and mutation frequency decline processes (which are carried out with reduced efficiency by the hor- strain) are not involved in the actual interaction phenomenon. It is clear, however, that the component of u.v. damage which is involved is subject to the excision-repair and/or mutation frequency decline processes since the hcr- strain yields interaction-mutants at very much lower doses of u.v. than the $\mathrm{hcr}^{+}$. This is presumably because more of the u.v. lesions involved in interaction are present for the necessary period of time after irradiation in the her- than in the her ${ }^{+}$strain.

It is difficult to invoke a mechanism to explain the nature of the interference in repair capacity. The responses obtained seem to be similar to those observed by Haynes (1964) who studied the lethal effects of combined u.v.-and X-irradiations. He interpreted the synergistic interaction as being due to the fact that the probability of repair of one potentially lethal lesion in DNA is reduced by the presence of other 
defects within some given distance of it. Equally one can assume that the interference is due to there being some steps in common in the repair systems for both u.v. and $\gamma$ lesions.

The authors acknowledge the efficient technical assistance of Mrs J. Potter, Mr J. Law and Miss Rachel Dennis.

\section{REFERENCES}

Ashwood-Smith, M. J., \& Bridges, B. A. (1966). Ultraviolet mutagenesis in Escherichia coli at low temperatures. Mutation Res. 3, 135.

BAPTIST, J. E., HAYNes, R. H. \& URETZ, R. B. (1966). Mechanism of u.v.-X-ray interaction in E. coli B/r. Effect of 5-bromouracil incorporation. Radiation Res. 27, 544.

BRIDGES, B. A., (1966). A note on the mechanism of u.v. mutagenesis in Escherichia coli. Mutation Res. 3, 273.

Bridges, B. A. \& Munson, R. J. (1964). Temperature, time and X-ray mutagenesis in Escherichia coli. Mutation Res. 1, 362.

Bridges, B. A. \& Munson, R. J. (1966). Excision-repair of DNA damage in an auxotrophic strain of Escherichia coli. Biochem. biophys. Res. Commun. 22, 268.

Bridges, B. A., Munson, R. J., Arlett, C. F. \& Davies, D. R. (1967). Interaction between ultraviolet light and $\gamma$-radiation damage in the induction of mutants of Escherichia coli: the effect of some modifying treatments. J. gen. Microbiol. 46, 339.

Doneson, I. N. \& SHANkel, D. M. (1964). Mutational synergism between radiations and methylated purines in Escherichia coli. J. Bact. 87, 61.

HAAS, F. L. \& DOUDNEY, C. O. (1957), A relation of nucleic acid synthesis to radiation-induced mutation frequency in bacteria. Proc. natn. Acad. Sci., U.S.A. 43, 871.

HAYNES, R. H. (1964). Molecular localization of radiation damage in relation to bacterial inactivation. In Physical Processes in Radiation Biology, p. 51. London: Academic Press.

HILL, R. F. (1965). Ultraviolet-induced lethality and reversion to prototrophy in Escherichia coli strains with normal and reduced dark repair ability. Photochem. Photobiol. 4, 563.

KADA, T., BRUN, E. \& \& MARCOVICH, H. (1960). Comparaison de l'induction de mutants prototrophes par les rayons $\mathrm{x}$ et u.v. chez Escherichia coli $\mathrm{B} / \mathrm{r}$ Try-. Ann. Inst. Pasteur 99, 547.

LIEB, M., (1960). Deoxyribonucleic acid synthesis and ultraviolet induced mutation. Biochim. biophys. Acta 37, 155.

Munson, R. J. \& BRIDGES, B. A. (1966a). Site of lethal damage by ionising radiation in Escherichia coli $\mathrm{B} / \mathrm{r}$ growing exponentially in minimal medium. Nature, Lond. $210,922$.

Munson, R. J. \& BRIDGes, B. A. (1966 b). Non-photoreactivating repair of mutational lesions induced by ultraviolet and ionizing radiations in Escherichia coli. Mutation Res. 3, 461.

SETLow, R. B. (1964). Physical changes and mutagenesis. J. cell. comp. Physiol. 64, (Suppl. 1), 51.

Swanson, C. P. (1952). The effect of supplementary factors on the radiation induced frequency of mutations in Aspergillus terreus. J. cell. comp. Physiol. 39, (Suppl. 1), 27.

WeAtherWaX, R. S. \& LANDMAN, O. E., (1960). Ultraviolet light induced mutation and deoxyribonucleic acid synthesis in Escherichia coli. J. Bact. 80, 528.

WITKIN, E. M., (1961). Modification of mutagenesis initiated by ultraviolet light through post-treatment of bacteria with basic dyes. J. cell. comp. Physiol. 58, (Suppl. 1), 135. 